\title{
Star polymer/water solutions: new experimental findings
}

\author{
C.Branca, S.Magazù, F.Migliardo \\ Dipartimento di Fisica and INFM, Università di Messina, \\ PO Box 55, I-98166 Messina, Italy
}

Received February 4, 2002

The purpose of the present work is to highlight a number of recent experimental results that have contributed significantly to the research area of star polymer. Firstly we will refer to a very impressive SANS work by J.Peyrelasse, C.Perreur, J.-P.Habas and J.François which is focused on the study of the structural properties of aqueous solutions of a star copolymer of PEO and PPO by Small Angle Neutron Scattering. Next, we will refer to some experimental advances reported in the work by R.Triolo, V.Arrighi, A.Triolo, P.Migliardo, S.Magazù, J.B.McClain, D.Betts, J.M.DeSimone, H.D.Middendorf, which deals with a study of some dynamical properties of PS- $b$-PFOA aggregates in supercritical $\mathrm{CO}_{2}$ by Quasi Elastic Neutron Scattering.

Key words: small angle neutron scattering, phase diagram, quasi elastic neutron scattering, diffusive dynamics

PACS: $61.12 . E x, 66.10 .-x$

\section{Introduction}

Today star polymers are the subject of different investigations due to their wide employment in manifold industrial sectors [1,2]. The fields of application of these compounds involve thermoplastic elastomers, rheology control agents, viscosity (index) modifiers, surfactants, lubricants, motor oil additives, coating and/or paint additives [1]. Furthermore, new star-polymer based gels have been created: their potential applications include removing substances such as cholesterol from the blood and delivering high concentrations of drugs to specific areas in the human body, such as tumors. Finally, since some star polymers have been shown to be non-toxic, they have great prospects in controlled release applications. In particular, large numbers of functional groups in a relatively small volume could be used to immobilize enzymes [3].

This paper presents a representative sampling of experimental findings which, within the wide research field of star polymers, have been the subject of considerable 
scientific scrutiny. The selection criterion has taken into account the contents of the other contributions to the volume as well as the fact that neutron scattering, due to the space time scale to which it is sensitive, due to the direct neutronnucleous interaction mechanism, and due to the selection options offered by isotopic substitution and by contrast techniques, has revealed to be successful in order to reach a fairly accurate physical picture.

In particular, firstly we will refer to a very impressive work entitled "Determination of the structure of the organized phase of PEO-PPO-PEO in aqueous solutions by small-angle neutron scattering under flow" by J.Peyrelasse, C.Perreur, J.P.Habas and J.François (Phys. Rev. E, in press), which is focused on the structural properties of aqueous solutions of a star copolymer of polyethylene oxide, PEO, and polypropylene oxide, PPO.

Successively, we will shortly refer to a paper entitled "QENS from Polymeric Micelles in Supercritical $\mathrm{CO}_{2}$ " by R.Triolo, V.Arrighi, A.Triolo, P.Migliardo, S.Magazù, J.B.McClain, D.Betts, J.M.DeSimone, H.D.Middendorf, which deals with some dynamical properties of PS- $b$-PFOA aggregates in $\mathrm{CO}_{2}[\mathrm{PS}=$ polystyrene; $\mathrm{PFOA}=\operatorname{poly}(1,1$-dihydroperfluorooctylacrylate $)]$ as a function of pressure and temperature.

\section{Results and discussion}

\subsection{Study of PEO-PPO-PEO structure by SANS}

Peyrelasse et al., in a very highlighting work, study the structure and the rheological properties of aqueous solutions of Tetronic $908^{\circledR}$. This latter compound is a four-branched star copolymer comprised of PEO and PPO blocks fixed on an aliphatic diamine. For the SANS measurements, performed at the laboratoire Léon Brillouin, CEA de Saclay (France) on the PAXY spectrometer, Tetronic ${ }^{\circledR}$ from BASF consisting of poly(ethylene oxide), PEO, and poly(propylene oxide), PPO blocks joined to an aliphatic diamine has been used. In particular, the investigated sample was T908 $(M=25000 \mathrm{~g} / \mathrm{mol})$. The mean numbers of EO and PO units per branch are respectively $x=114$ and $y=21$ and it was used without further purification.

Above critical conditions of temperature and concentration, the micelles formed by the aggregation of PPO units, self-organize themselves in particular structures. While small angle neutron scattering characterizations (SANS) performed with static conditions demonstrate the organization of the medium, the experimental results do not allow a distinction between either simple cubic or body centered cubic structures. However, SANS measurements realized under shear produce characteristic diffraction diagrams.

Some models based on this kind of star polymers are today present in literature. As an example, Mortensen et al. [4-6] proposed that the micelles consist of a core of PPO with a radius $R_{c}$ containing a small percentage of PEO, whereas Liu et al. [7] proposed a two-shell model made up of PPO in the core and PEO and water 


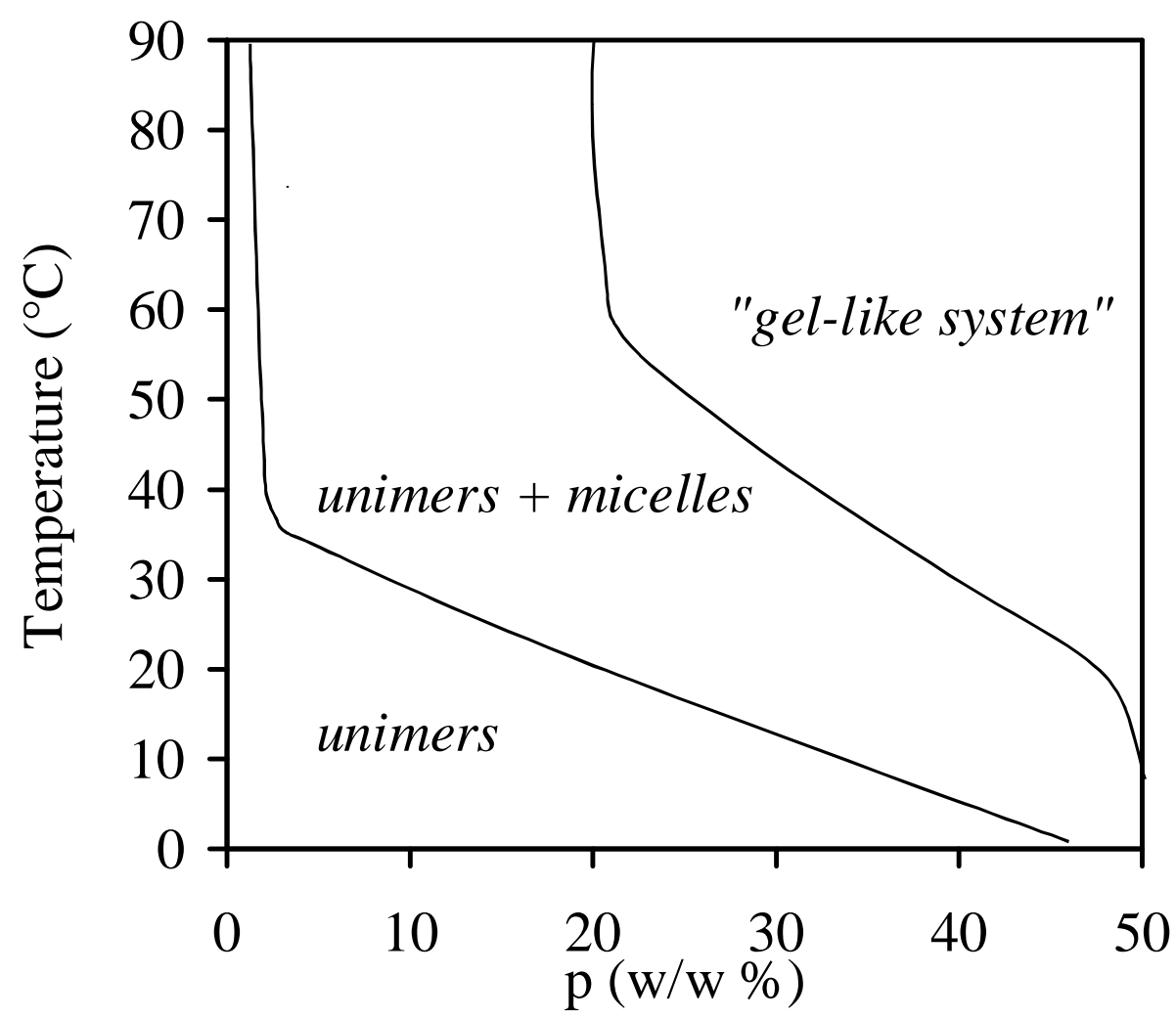

Figure 1. Phase diagram of aqueous solutions of Tetronic 908.

in the corona. Unfortunately, the different models cannot explain the SANS results obtained with T908 solutions. For this reason, in the analysis procedure, a three layer model has been used, showing an equilibrium state between unimers and micelles. This model perfectly fits the experimental curves $I(q)$ [8-9].

In a previous publication [8], from viscosimetric measurements, the phase diagram of the aqueous solution of T908 (figure 1) has been characterized. This study demonstrated that in zone 1 , the solution contains only unimers. In zone 2, there is an equilibrium between unimers and micelles which moves towards micelles when the temperature increases. The limit between zone 1 and zone 2 makes it possible to define the critical micelle temperature (CMT) for each concentration. These results were also confirmed by other techniques (light scattering, fluorimetry, SANS). The transition between zones 2 and 3 is characterized by a divergence of the viscosity above the temperature $T_{\mathrm{d}}$, which depends on concentration. Measurements by mechanical spectroscopy clearly showed that this phenomenon is not a sol-gel transition. Indeed, beyond the temperature $T_{\mathrm{d}}$, the solutions, when exposed to the lowest frequencies, exhibited a rheological behaviour similar to that of entangled polymers [8].When the temperature was increased, the crossover point moved towards the low frequencies i.e. long relaxation times.

SANS measurements were taken in different zones of the phase diagram. In zone 1, which corresponds to unimers in solution, the $I(q)$ spectra are flat. In contrast, in zone 2 of the diagram, $I(q)$ reveals a peak whose amplitude increases with 


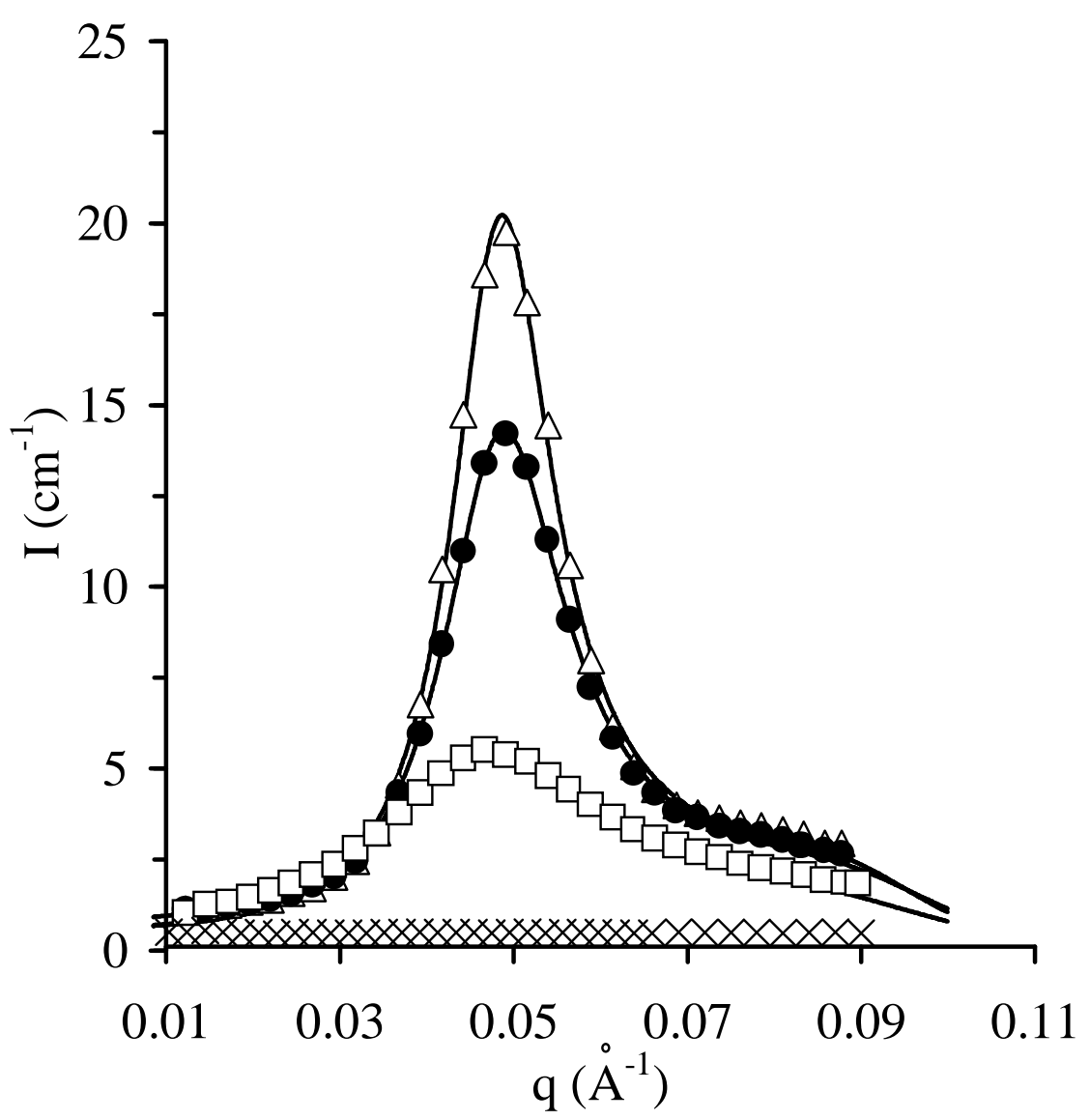

Figure 2. Effect of temperature on scattered intensity of a $30 \%$ solution: $\times-$ $5{ }^{\circ} \mathrm{C}, \square-20{ }^{\circ} \mathrm{C}, \bullet-30{ }^{\circ} \mathrm{C}, \triangle-37{ }^{\circ} \mathrm{C}$.

temperature (figure 2). This peak corresponds to the formation of micelles while its rise in intensity is the result of an increase in the volume fraction of micelles. With the hard spheres model [8-9] to fit the peaks, several parameters can be determined such as the radius of the micelles, their volume fraction, the fraction of unimers in equilibrium with the micelles, and the fraction of water contained within the micelles. Figure 2 shows a very good match between the model and the experimental results.

In zone 3 of the phase diagram, Bragg-peaks are revealed, thus showing a transition to an organized phase. The $2 \mathrm{D}$ pattern is isotropic. This is equivalent to a crystal powder diffraction diagram and clearly indicates that the crystals exhibit all possible orientations in space (figure 3 ).

It is noticeable that in zone 2 of the diagram, there are no observable differences between the results from samples under static or shear conditions, while in zone 3 , where the micelles are organized and form a cubic lattice, the differences are fundamental.

It is possible to determine the nature of the network and the row [uvw] around which the crystals are oriented in a relatively simple way. If $r_{1}$ is the radius of the first circle, the scattering angle $\theta_{1}$ for the spots belonging to this circle is given by: 


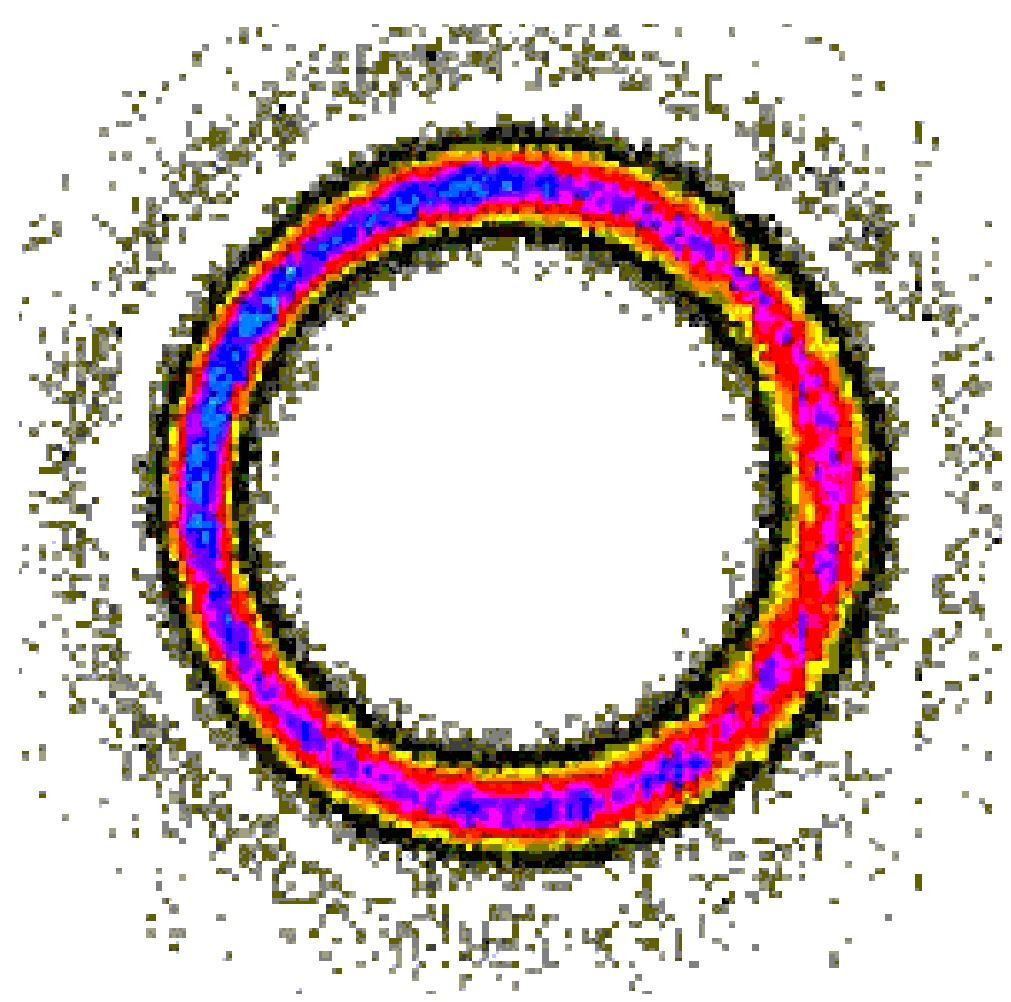

Figure 3. $2 \mathrm{D}$ diffraction diagram of a $40 \%$ solution at $T=70{ }^{\circ} \mathrm{C}$.

$\tan \theta_{1}=r_{1} / D$. As the angles are very small, one obtains:

$$
\sin \frac{\theta_{1}}{2}=\frac{\lambda}{2 d_{h k l}}=\frac{r_{1}}{2 D} \quad \text { and then } \quad \frac{r_{1}}{\Delta}=\frac{L}{d_{h k l}}
$$

Under experimental conditions, a value of $\Delta=12.1 \mathrm{~cm}$, then $r_{1} / \Delta=1.23$ has been obtained.

If the "crystals" are $b c c$ and oriented with the row [111] in the direction of the flow then:

$$
L=\frac{a \sqrt{3}}{2} \Rightarrow \frac{r_{1}}{\Delta}=\frac{\sqrt{6}}{2}=1.22 .
$$

One can notice that the latter hypothesis is in perfect agreement with the experimental determination, and this solution is the only one possible.

Since the network is a body centered cubic one, the spots located on the first circle are of the type $\{110\}$, those of the second circle are of the type $\{200\}$ and those of the third circle are of the type $\{211\}$. No spots were observed on the fourth circle because of the $q$ domain limitation.

The crystals move towards the row [111] in the direction of the flow. The vertical layer, which represents the symmetrical axis of the figure of diffraction corresponds to $n=0$. It must, therefore, contain the spots $h+k+l=0$ (equation 1) i.e. $\{1 \overline{1} 0\}$ and $\{2 \overline{1} \overline{1}\}$ or $\{\overline{2} 11\}$. These spots are visible on the first and the third circles, which is satisfactory. 
On the first layer one must have $h+k+l=2$ (for the bcc lattice the sum of the three indices must be even). The possible spots are $\{110\},\{200\}$ or $\{2 \overline{1} 1\}$. The first one $\{110\}$ and $\{200\}$ are detected. The spot $\{2 \overline{1} 1\}$ on the third circle is not visible, but there is a spot with a low intensity located at the limit of the accessible $q$ domain.

On the second layer $h+k+l=4$. Thus, the first spot must be of type $\{211\}$, and is present on the third circle. The above considerations show that it is possible to index all the spots that appear on the pattern. It is then possible to predict the angular positions of different spots. For example, the six spots from the first ring must be separated by four angles of $54.7^{\circ}$ and by two angles of $70.5^{\circ}$; this is still in perfect agreement with the experimental observations.

It is also possible to check these calculations by evaluating the equidistance $\Delta$ between the layers. $\Delta=12.1 \mathrm{~cm}$ and the distance between two nodes in the direction [111], which is the diagonal of the cube, is given by: $L=D \lambda / \Delta$, by obtaining $L=158 \AA$ and since $a=2 L / \sqrt{3}, a=183 \AA$, in perfect agreement with previous determinations.

Knowing $L$, one can check that the hypothesis $(L / \lambda)^{2} \gg i^{2}$ is validated since $(L / \lambda)^{2}=693$ and that for the second layer $i^{2}=4$. In a previous paper [8], the radius $R_{m}$ and the volume fraction $\Phi$ of micelles as a function of temperature and weight percentage have been determined. For instance, for a $30 \%$ solution at $T=52{ }^{\circ} \mathrm{C}$, (zone 3 of the phase diagram), $R_{m}=71.5 \AA$ and $\Phi=0.48$ has been obtained. Since the bcc lattice has two micelles by mesh, it is possible to reestimate the lattice size as in:

$$
a=\left(2 \frac{4 \pi R_{\mathrm{m}}^{3}}{3 \Phi}\right)^{1 / 3}
$$

The calculated value, $a=185 \AA$, is in perfect agreement with the previous analysis $[8]$.

\subsection{Dynamical properties of PS- $b$-PFOA aggregates in $\mathrm{CO}_{2}$}

The QENS measurements were performed by using the pulsed-source spectrometer IRIS [10] at ISIS (RAL, Chilton, UK) on PS- $b$-PFOA aggregates in $\mathrm{CO}_{2}$ at pressures of 200 and 350 bar and temperatures between 293 and $313 \mathrm{~K}$ [PS=polystyrene; $\mathrm{PFOA}=\operatorname{poly}(1,1$-dihydroperfluorooctylacrylate)]. These micelle-like aggregates consist of dense, globular cores of $\mathrm{CO}_{2}$-insoluble material surrounded by a "corona" of PFOA surfactant chains whose $\mathrm{CO}_{2}$-philic groups interface with the supercritical solvent.

A block copolymer composed of $\mathrm{CO}_{2}$-phobic polyvinylacetate (PVAc, $10.3 \mathrm{kDa}$ ) and a $\mathrm{CO}_{2}$-philic fluorinated octyl acrylate (PFOA, $43.1 \mathrm{kDa}$ ) of average effective molecular weight $90.4 \mathrm{kDa}$ has been studied by using time of flight small angle neutron scattering (SANS) by Triolo et al. [11] in supercritical $\mathrm{CO}_{2}\left(\mathrm{sc}-\mathrm{CO}_{2}\right)$ at $65{ }^{\circ} \mathrm{C}$. A sharp unimer-micelle transition is obtained due to the tuning of the solvating ability of sc- $\mathrm{CO}_{2}$ by profiling pressure, so that the block copolymer, in a semidilute solution, finds $\mathrm{sc}-\mathrm{CO}_{2}$ a good solvent at high pressure and a poor solvent at low 
pressure. At high pressures, the copolymer is in a monomeric state with a random coil structure. However, on lowering the pressure, aggregates are formed with a structure similar to aqueous micelles, the hydrocarbon segments forming the core and the fluorocarbon segments forming the corona of the micelle. This unimeraggregate transition is driven by the gradual elimination of $\mathrm{CO}_{2}$ molecules solvating the hydrocarbon segments of the polymer.

In a number of SAXS and SANS studies, radii of gyration, core radii, thickness of surfactant shells, polydispersities and other parameters have been determined.[11] The results show that PS- $b$-PFOA micelles can be modelled as core-shell structures with core radii $R_{1} \approx 25-30 \AA$ and outer radii $R_{2}=70-90 \AA$, depending on copolymer size and concentration. At higher $Q$ up to $0.3 \AA^{-1}$, where scattering from smaller structures becomes dominant, SAXS curves were interpreted by scattering from rodlike segments of the PFOA backbone.[12] The structural data suggest distinguishing between two time scale regions:

(i) A relatively slow one quantifying the Brownian dynamics of micelles as a whole, i.e. their rotational and translational motions, and

(ii) a faster one relating to localised diffusive modes and segmental dynamics of the anchored, finite-length PFOA chains in the "corona" region [11].

QENS measurements from PS-b-PFOA aggregates in supercritical $\mathrm{CO}_{2}$ have evidenced localized diffusive modes and segmental dynamics of the anchored, finitelength PFOA chains. These aggregates consist of dense cores of $\mathrm{CO}_{2}$-insoluble polystyrene surrounded by a "corona" of PFOA surfactant molecules whose $\mathrm{CO}_{2}$-philic groups interface with supercritical $\mathrm{CO}_{2}$. An effective diffusion coefficient of $\approx$ $0.8 \cdot 10^{-6} \mathrm{~cm}^{2} / \mathrm{sec}$ has been evaluated for $Q \sim 0.6 \AA^{-1}$. For $Q>1.5 \AA^{-1}$, the wings reflect contributions due to a distribution of faster, more localised chain modes.

In constructing $S_{\text {inc }}(Q, \omega)$ models it is essential to distinguish between protons that are immobile or effectively immobile (relative to the longest time scale probed), and protons in translationally and/or rotationally mobile groups contributing to the quasielastic broadenings observed. For IRIS, with data of excellent statistics, width changes down to a few percent are observable, corresponding to times $\tau_{\text {res }}$ of the order of 1 ns.

All contributions to $S_{\text {inc }}(Q, \omega)$ carry Debye-Waller factors $\exp \left(-Q^{2}\left\langle u_{p}^{2}\right\rangle\right)$. Here $\left\langle u_{p}^{2}\right\rangle$ is an average cross-section weighted mean-square vibrational displacement. Difference spectra $\Delta S_{\text {inc }}(Q, \omega)$ from $30 \%$ solutions of PS- $b$-PFOA in sc-CO $\mathrm{CO}_{2}$ at $20{ }^{\circ} \mathrm{C}$ and $40{ }^{\circ} \mathrm{C}$ and pressures of 200 to 350 bar revealed four lineshape contributions:

(i) A slight broadening of the central elastic peak, increasing with $Q$ from a few $\mu \mathrm{eV}$ at low $Q$ to values comparable with the resolution width at high $Q$;

(ii) strongly $Q$-dependent wing broadenings with widths of the order of $100 \mu \mathrm{eV}$;

(iii) small but noticeable intensity increases with $\mathrm{Q}$ on the lower flanks of the q.e. peaks, at energy transfers intermediate between (i) and (ii); 


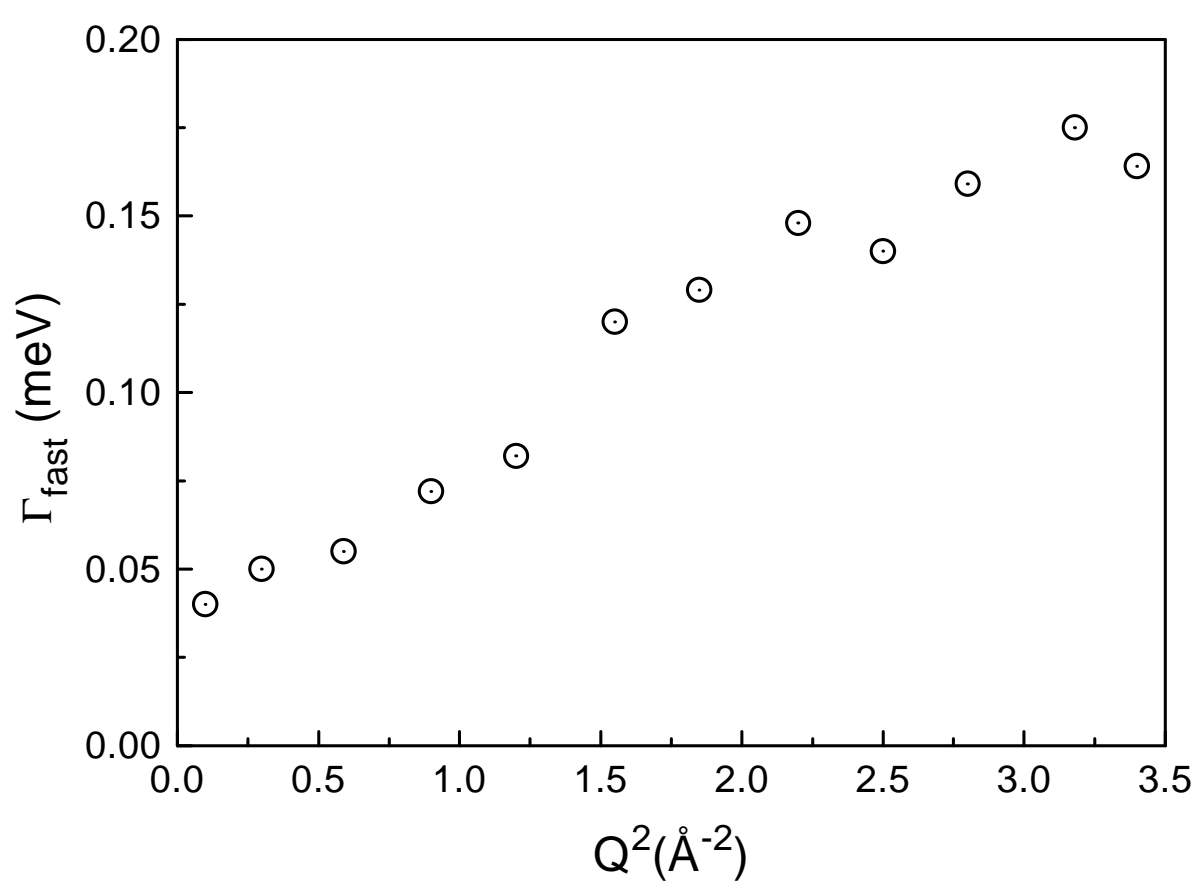

Figure 4. $\Gamma_{\text {fast }}$ vs. $Q^{2}$ (see text for details).

(iv) a very broad, essentially flat and background-like underlying component with a $Q$-dependence that could (at least partially) be due to inelastic processes.

The measured $\Delta S(Q, \omega)$ reveals that outside the central peak and the lower flank regions, the spectra are fairly well represented by the equation

$$
S_{\mathrm{inc}}(Q, \omega)=A_{0}(Q) \delta(\omega)+\left(1-A_{0}(Q)\right) S_{q e}(Q, \omega)
$$

if $S_{\mathrm{qe}}$ is taken to be a Lorentzian (for restricted translational motions) convoluted with a rotational contribution (Sears model).

Furthermore, apart from the inability of equation (1) to account for the small but distinct central peak broadenings, the lower flanks $<25 \mu \mathrm{eV}$ give significant deviations and cannot be modelled satisfactorily in this way.

The $\Gamma_{\text {fast }}(Q)$ at low to intermediate $Q$ is plotted in figure 4 . The next step is a simple ad hoc extension of equation (1) to account for central peak broadenings by allowing the $\delta$-function to broaden and thus to model slow translational motions, as described by a plain Lorentzian of width $\Gamma_{\text {slow }}(\mathrm{HWHM})$. Thus, the $\delta$-function is replaced by $A_{\mathrm{o}} L_{\text {slow }}(Q, \omega)$. To check the consistency of assuming a Lorentzian, the $60 \%$ and $70 \%$ level widths are shown along with the $50 \%$ widths $\Gamma_{\text {slow }}$ (HWHM). From the slope of $\Gamma_{\mathrm{m}}$ as a function of $\mathrm{Q}^{2}$ one obtains an effective diffusion coefficient $D_{\text {eff }} \approx 0.8 \times 10^{-6} \mathrm{~cm}^{2} / \mathrm{sec}$. This could be interpreted as a measure of the overall micelle mobility; however, the errors in this analysis are large (note in particular the non-zero $Q=0$ intercept) and $\mu \mathrm{eV}$-resolution data down to at least $0.1 \AA^{-1}$ are clearly needed. Apart from this, it is difficult to give precise meaning to the qualification "effective" without MD simulations of the dynamics of such core-shell structures. 
More sophisticated analytical expressions for $S_{\text {inc }}(Q, \omega)$ should be able to describe a distribution of relaxation times, instead of one or more averaged times as it is in composite Lorentzian models [13]. Scattering laws of this kind are a priori more appropriate to the morphology inferred from structural studies, i.e. they allow for the fact that surfactant chains are investigated that are not only anchored but also polydisperse with a broad length distribution. The main feature of more realistic $S_{\text {inc }}(Q, \omega)$ will be a distribution of relaxation times for the rod-like groups along the chains.

\section{Acknowledgement}

The authors greatly thank Jean Peyrelasse, Christelle Perreur, Jean-Pierre Habas and Jeanne François who have kindly furnished a precious support providing their published data, and some of the figures shown in this work. The authors also thank the Journal Physical Review E for the copyright permission.

\section{References}

1. Grest G.S., Fetters L.J., Huang J. S., Richter D. // Adv. Chem. Phys., 1996, vol. XCIV, p. 67.

2. Storey R.F., Nelson M.E. // Applied Polymer Science, 1997, vol. 66, p. 151.

3. Wang C.-H, J.U, Teo C.S., Lee T. // Controlled Release, 1999, vol. 61, p. 21.

4. Mortensen K. // Macromolecules, 1997, vol. 30, p. 503.

5. Mortensen K., Brown W., Jorgensen E. // Macromolecules, 1994, vol. 27, p. 5654.

6. Mortensen K. // J. Phys.: Condens. Matter, 1996, vol. 8, p. A103.

7. Liu Y.C., Chen S.H., Huang J.S. // Phys. Rev. E, 1996, vol. 54, p. 1698.

8. Perreur C, Habas J.P., Lapp A., Peyrelasse J., François J. // Phys. Rev. E, 2001, vol. 63, p. 31505 .

9. Perreur C., Habas J.P., Lapp A., François J., Peyrelasse J. - In: $3^{\text {rd }}$ International conference on polymers and intercalates. Besançon, Aout 2000.

10. Carlile C.J., Adams M.A. // Physica B, 1992, vol. 182, p. 431.

11. Triolo A., Triolo F., F. Lo Celso, Betts D.E., McClain J.B., de Simone J.M., Wignall G.D., Triolo R. // Phys. Rev. E, 2000, vol. 62, No. 4, p. 5839.

12. Fulton J.L. // Langmuir, 1995, vol. 11, p. 4241.

13. Middendorf H.D. // Biol. Chem., 1994, vol. 53, p. 145. 


\title{
Зіркові полімери/водні розчини: нові експериментальні дані
}

\author{
К.Бранка, С.Магацу, Ф.Мільярдо
}

Кафедра фізики та ІНФМ, Університет Месіни, а/с 55, І-98166 Месіна, Італія

Отримано 4 лютого 2002 p.

Метою даної роботи є висвітлення ряду недавніх експериментальних результатів, що зробили значний внесок у фізику зіркових полімерів. Спочатку ми звернемось до дуже вагомої роботи Дж.Пейреласе, С.Перо, Дж.-П.Габас і Дж.Францес, яка присвячена вивченню структурних властивостей водних розчинів зіркових кополімерів РЕО i РPО за допомогою розсіяння нейтронів на малих кутах. Далі ми згадаємо деякі експериментальні здобутки, викладені в роботі Р.Тріоло, В.Аріджі, П.Мільярдо, С.Магацу, Дж.Б.МакКлайна, Д.Бетса, Дж.М.ДеСімоне, Г.Д.Мідендорфа, які стосуються вивчення деяких динамічних властивостей агрегатів PS- $b$-PFOA у надкритичному $\mathrm{CO}_{2}$ методом квазіпружного розсіяння нейтронів.

Ключові слова: розсіяння нейтронів на малих кутах, фазова діаграма, квазіпружне розсіяння нейтронів, дифузійна динаміка

PACS: $61.12 . E x, 66.10 .-x$ 